\title{
PELAKSANAAN PENDIDIKAN DAN PELATIHAN BAGI PENYULUHAN PERTANIAN OLEH BALAI PELATIHAN PERTANIAN JAMBI BERDASARKAN PERATURAN MENTERI PERTANIAN NOMOR : 49/PERMENTAN/OT.140/9/2011
}

\author{
Mhd. Ansori ${ }^{1}$ \\ Universitas Batanghari J1. Slamet Riyadi Brorni Kota Jambi (0741) 65351
}

\begin{abstract}
Abstrak
Dalam rangka mengantisipasi tantangan perubahan lingkungan strategis yang berkembang di abad ini diperlukan sumber daya manusia yang siap pakai, profesional, inovatif, kreatif, dan berwawasan global. Pendidikan dan pelatihan merupakan salah satu upaya menjawab tantangan tersebut di atas, sekaligus menjawab derasnya tuntutan masyarakat untuk memperoleh pelayanan prima dalam pelayanan jasa pendidikan dan pelatihan serta informasi untuk meningkatkan produktivitas, efektivitas, dan efisiensi usaha agribisnis para pelaku utama dan pelaku usaha pertanian di pedesaan. Tulisan ini mengkaji masalah pokok yaitu Apakah realisasi peserta diklat sudah sesuai dengan hasil Identifikasi Kebutuhan Diklat (IKD).

Kata Kunci : Pendidikan dan Pelatihan, Penyuluhan Pertanian, Balai Pelatihan Pertanian
\end{abstract}

\begin{abstract}
In order to anticipate the challenges of the evolving strategic environment changes in this century of human resources required that ready-made, professional, innovative, creative, and insightful global. Education and training is one of the attempts to answer these challenges, as well as answer the new demands of society to obtain excellent service in the Ministry of education and training services as well as information to improve productivity, effectiveness, and efficiency of the main perpetrators of agribusiness ventures and agricultural trade in the countryside. This paper examines the principal issues, namely Whether the realization of the training participants were already in compliance with the results of the identification of Training Needs (IKD).
\end{abstract}

Keywords: education and training, agricultural extension, Agricultural Training Hall

\section{PENDAHULUAN}

Indonesia mempunyai potensi sumber daya alam pertanian yang sangat besar dimana sumber daya alam tersebut telah menjadi sumber penghidupan bagi sebagian besar bangsa dari dahulu hingga sekarang, maka dari itu Indonesia dipandang sebagai negara agraris. Mengingat bahwa luas daratan yang dimiliki Indonesia cukup luas dan tingkat konsumsi yang tinggi terhadap hasil pertanian maka sektor pertanian harus menjadi perhatian khusus Pemerintah Indonesia. ${ }^{2}$

Dalam rangka mengantisipasi tantangan perubahan lingkungan strategis yang berkembang di abad ini dengan issu globalisasi, desentralisasi,

\footnotetext{
${ }^{1}$ Mhd. Ansori, SH,MH, Dosen Tetap PS Ilmu Hukum Fakultas Hukum Universitas Batanghari Jambi

${ }^{2}$ Balai Pelatihan Pertanian Jambi, Road Map BPP Jambi 2015-2019.
} 
demokratisasi, pembangunan berkelanjutan, dan perubahan iklim global diperlukan sumberdaya manusia yang siap pakai, profesional, inovatif, kreatif, dan berwawasan global, guna mewujudkan pertanian yang tangguh, produktif, efisien, berdaya saing dan dapat meningkatkan kesejahteraan petani.

Pembangunan sektor pertanian sampai saat ini masih memegang peranan yang sangat penting. Sektor pertanian tersebut digambarkan dalam kontribusi nyata sebagai penyedia bahan pangan dan bahan baku industri kecil dan menengah, penghasil devisa negara, penyerap tenaga kerja, sumber utama pendapatan rumah tangga pedesaan, penyedia bahan pakan dan bioenergi, serta berperan dalam upaya penurunan emisi gas rumah kaca. ${ }^{3}$

Tantangan yang dihadapi angkatan kerja di bidang pertanian pada saat ini adalah kesiapan untuk menghadapi pasar kerja yang semakin kompetitif. Oleh sebab itu diperlukan adanya upaya peningkatan kapasitas dan kompetensi penyuluh pertanian agar memiliki kompetensi kerja, moral dan etika dalam melaksanakan tugas dan pekerjaannya. Pendidikan dan pelatihan merupakan salah satu upaya menjawab tantangan tersebut di atas, sekaligus menjawab derasnya tuntutan masyarakat untuk memperoleh pelayanan prima dalam pelayanan jasa pendidikan dan pelatihan serta informasi untuk meningkatkan produktivitas, efektivitas, dan efisiensi usaha agribisnis para pelaku utama dan pelaku usaha pertanian di pedesaan.

Sementara itu, untuk mengantisipasi dampak iklim global, Kementerian Pertanian melakukan upaya-upaya dalam rangka adaptasi dan mitigasi perubahan iklim global melalui pemberdayaan sumberdaya manusia pertanian di pedesaan, pendidikan dan pelatihan bagi aparatur pertanian, terutama bagi penyuluh pertanian. Berdasarkan hal-hal tersebut di atas, maka Kementerian Pertanian menetapkan tujuan pembangunan pertanian 2015-2019 adalah:

1. Meningkatkan produksi, produktifitas dan mutu produk pertanian;

2. Mewujudkan sistem pertanian berbasis bioindustri berkelanjutan yang berbasis sumberdaya lokal;

3. Menumbuhkembangkan diversi pangan dan peningkatan gizi;

4. Meningkatkan nilai tambah, daya saing, ekspor subtisusi impor produk pertanian;

5. Meningkatkan pendapatan serta kesejahteraan petani. ${ }^{4}$

Badan Penyuluhan dan Pengembangan Sumberdaya Manusia (SDM) Pertanian, merupakan lembaga yang bertanggung jawab dalam peningkatan kapasitas dan kompetensi aparatur pertanian melalui pendidikan dan pelatihan pertanian.

Guna meningkatkan kontribusi sektor pertanian dalam pembangunan perekonomian, kuncinya adalah dengan memaksimalkan potensi sumberdaya alam yang ada serta mempunyai sumberdaya manusia (SDM) yang berkualitas dengan ciri: mandiri, profesional, kreatif, inovatif, dan berwawasan global. Salah satu upaya pengembangan SDM pertanian adalah melalui kegiatan pendidikan dan pelatihan yang terencana dan sistematis. Kegiatan pendidikan dan pelatihan ini dilaksanakan di 10 balai yang tersebar di Indonesia, salah satunya adalah Balai Pelatihan Pertanian Jambi. ${ }^{5}$

\footnotetext{
${ }^{3}$ Pusat Pelatihan Pertanian, Rencana Strategis 2015-2019, hlm. 1.

${ }^{4}$ Pusat Pelatihan Pertanian, op. cit. hlm. 1.

${ }^{5}$ Balai Pelatihan Pertanian Jambi, op. cit.
} 
Untuk mewujudkan pembagunan pertanian, upaya peningkatan kompetensi dan profesionalisme SDM pertanian perlu lebih diprioritaskan. Peningkatan kompetensi dan profesionalisme penyuluh pertanian di lingkungan Badan Penyuluhan dan Pengembangan Sumberdaya Manusia Pertanian (BPPSDMP), telah diselenggarakan melalui diklat-diklat berbasis kompetensi sesuai dengan jabatan yang dipangku berdasarkan Peraturan Menteri Pertanian Nomor: 49/Permentan/OT.140/9/2011 Tentang Pedoman Pendidikan dan Pelatihan Pertanian Aparatur dan Non Aparatur. Diklat bagi penyuluh pertanian meliputi Diklat Fungsional, dan Diklat Teknis Pertanian. ${ }^{6}$

Balai Pelatihan Pertanian (BPP) Jambi yang dibentuk melalui Peraturan Menteri Pertanian Nomor: 21/Permentan/OT.140/2/2007 tanggal 19 Februari 2007, mempunyai kewenangan melaksanakan pelatihan di bidang pertanian. Keberadaannya diharapkan mampu mendukung pembangunan pertanian dalam pengembangan agribisnis berbasis komoditas unggulan, oleh karena itu peran BPP Jambi harus lebih dioptimalkan. Keberhasilan BPP Jambi dalam mendukung visi mewujudkan sistem pertanian-bioindustri berkelanjutan yang menghasilkan beragam pangan sehat dan produk bernilai tambah tinggi berbasis sumber daya lokal untuk kedaulatan pangan dan kesejahteraan petani harus didukung oleh sarana dan prasarana yang memadai serta sumberdaya manusia yang berkualitas. Kualitas SDM yang memadai dan ketersediaan sarana dan prasarana merupakan salah satu faktor penentu keberhasilan dalam mendukung pembangunan pertanian.

Balai Pelatihan Pertanian (BPP) Jambi menyelenggarakan fungsi antara lain:

1. Pelaksanaan penyusunan bahan Standar Kompetensi Kerja (SKK) di bidang pertanian;

2. Pelaksanaan pelatihan fungsional di bidang pertanian bagi aparatur;

3. Pelaksanaan pelatihan teknis di bidang perkebunan dan teknologi lahan rawa bagi aparatur dan non aparatur pertanian dalam dan luar negeri;

4. Pelaksanaan pelatihan profesi di bidang perkebunan dan teknologi lahan rawa bagi aparatur dan non aparatur pertanian;

5. Pelaksanaan uji kompetensi di bidang pertanian;

6. Pelaksanaan penyusunan paket pembelajaran dan media pelatihan fungsional dan teknis di bidang pertanian;

7. Pelaksanaan pengembangan kelembagaan pelatihan pertanian swadaya. ${ }^{7}$

Agar suatu diklat dapat memenuhi kompetensi yang dibutuhkan oleh peserta diklat maka penyelenggara diklat harus mampu menuangkan komptensi yang dibutuhkan oleh unit kerja pengguna diklat ke dalam materi diklat. Sehingga, program diklat dan/atau materi yang diberikan dalam diklat mampu meniadakan dan/atau mengurangi kesenjangan kompetensi unit kerja pengguna diklat.

Identifikasi Kebutuhan Diklat (IKD) merupakan suatu proses untuk mengidentifikasi dan mengharmoniskan jenis-jenis diklat yang dibutuhkan oleh unit kerja pengguna diklat, baik di tingkat organisasi, jabatan, maupun individu dengan menterjemahkan kebutuhan kompetensi unit kerja pengguna diklat ke dalam suatu desain program diklat.

\footnotetext{
${ }^{6}$ Pusat Pelatihan Pertanian, loc. cit, hlm 2.

${ }^{7}$ Balai Pelatihan Pertanian Jambi, op.cit.
} 
Dengan IKD, maka penyelenggara atau pengelola diklat dapat menitikberatkan program-program diklat terhadap kebutuhan kompetensi utama dari peserta diklat. Dengan demikian, proses IKD merupakan suatu proses yang mutlak harus dilaksanakan oleh penyelenggara diklat. Proses ini terutama menyandingkan antara program diklat yang dirancang dengan kebutuhan kompetensi peserta diklat atau dengan kata lain mengharmoniskan desain program diklat dengan kebutuhan kompetensi peserta diklat. ${ }^{8}$

\section{Rumusan Masalah} berikut:

Adapun yang menjadi permasalahan dalam skripsi ini adalah sebagai

1. Apakah realisasi peserta diklat sudah sesuai dengan hasil Identifikasi Kebutuhan Diklat (IKD)?

\section{METODELOGI PENELITIAN}

\section{Lokasi Penelitian}

Penelitian ini dilakukan di Balai Pelatihan Pertanian Jambi, yang beralamat di jalan Jambi Palembang KM. 16, Desa Pondok Meja, Kecamatan Mestong, Kabupaten Muaro Jambi. Pertimbangan yang mendasari lokasi penelitian ini adalah adanya kemungkinan Balai Pelatihan Pertanian Jambi kurang maksimal dalam melaksanakan tugas dan fungsinya.

\section{Jenis Penelitian}

Penelitian ini merupakan suatu penelitian deskriptif dengan didukung data kualitatif, dengan demikian, spesifikasi penelitian yang penulis pergunakan dalam penelitian ini adalah bersifat empiris. ${ }^{9}$

3. Sumber Data

Dalam penelitian ini diperoleh sumber data antara lain berasal dari:

a. Penelitian lapangan

Merupakan penelitian yang dilakukan dengan mengumpulkan data dan informasi yang diperoleh langsung dari hasil pengamatan, penglihatan, dan pencatatan di lokasi penelitian. Hasil dari penelitian lapangan ini kemudian dijadikan sebagai data primer dalam penelitian ini.

b. Penelitian kepustakaan

Sebagai tindak lanjut dari hasil penelitian lapangan tersebut diatas, maka penelitian ini dilakukan dengan cara mempelajari dan memahami bukubuku/literatur, karya tulis para ahli terhadap peraturan perundang-undangan yang ada hubungannya dengan penulisan skripsi ini. Hasil dari mempelajari buku-buku dan lainnya kemudian dijadikan data skunder sebagai pedoman dalam penyusunan kerangka teoritis skripsi ini.

4. Teknik penarikan sampel

Teknik penarikan sampel yang digunakan adalah secara purposive sampling (sampel secara sengaja), yaitu pengambilan sampel berdasarkan

\footnotetext{
${ }^{8}$ http://docplayer.info/351397-Laporan-kajian-pedoman-penyusunan-analisis-kebutuhandiklat-akd-dan-identifikasi-kebutuhan-diklat-ikd-kerjasama-pt-idi-kajang-consultans-dengan.html diakses pada tanggal 1 maret, pukul 10.00 WIB

9 Sari Rahmawati, "Kinerja PD BPR Bank Pasar Kabupaten Boyolali”, diakses dari http://female.store.co.id/images/media/administrasi-negara-full.pdf, pada tanggal 17 Oktober 2015, pukul 20.07 WIB.
}

Pelaksanaan Pendidikan dan Pelatihan Bagi Penyuluhan Pertanian oleh Balai Pelatihan Pertanian Jambi Berdasarkan Peraturan Menteri Pertanian 
penilaian peneliti mengenai siapa-siapa saja yang pantas (memenuhi persyaratan) untuk dijadikan sampel. Dalam hal ini yang menjadi sampel penelitian adalah Kepala Balai Pelatihan Pertanian Jambi, dan Kepala Seksi Penyelenggaraan Pelatihan BPP Jambi.

5. Teknik Pengumpulan Data

Sesuai dengan bentuk penelitian kualitatif dari jenis sumber data yang digunakan, maka teknik pengumpulan data yang digunakan dalam penelitian ini adalah:

a. Observasi

Teknik pengumpulan data yang dilakukan dengan pengamatan dan pencatatan langsung di lokasi penelitian mengenai kegiatan yang ada dan sedang berlangsung.

b. Wawancara

Dalam penelitian ini dilakukan dengan mengadakan wawancara tatap muka yang diarahkan pada masalah tertentu dengan responden yang sudah dipilih untuk mendapatkan data yang diperlukan. Dalam wawancara ini, yang menjadi responden adalah:

1) Dr. Ir. Teddy Rachmat Muliady, M.M, selaku Kepala Balai Pelatihan Pertanian Jambi; dan

2) Purnadi, S.P., M.P, selaku Kepala Seksi Penyelenggaraan Pelatihan.

6. Teknik Analisis Data

Setelah data primer dan skunder dikumpulkan, selanjutnya dikategorikan, diklarifikasikan, ditabulasikan, dan diinterpretasikan. Tujuan analisa data adalah untuk menyederhanakan data kedalam bentuk yang lebih mudah dibaca kemudian dilanjutkan penafsiran data dimana penulis mengungkapkan dalam bentuk uraian-uraian dan penjelasan-penjelasan lainnya yang pada akhirnya dapat diambil suatu kesimpulan-kesimpulan, saran-saran sesuai dengan tujuan penelitian ini. ${ }^{10}$

\section{PEMBAHASAN}

\section{Realisasi Peserta Diklat}

Balai Pelatihan Pertanian (BPP) Jambi sebagai salah satu UPT Pusat di bawah Kementerian Pertanian mempunyai wilayah pelayanan yang meliputi Provinsi Aceh, Provinsi Sumatera Utara, Provinsi Sumatera Barat, Provinsi Riau, Provinsi Kepualauan Riau, dan Provinsi Jambi. Masing-masing provinsi tentunya memiliki penekanan yang berbeda dalam pembangunan sektor pertanian.

Keadaan ini menimbulkan perbedaan kebutuhan diklat sesuai dengan titik berat pembangunan sektor pertanian masing-masing provinsi. Sasaran program diklat BPP Jambi adalah sumberdaya manusia pertanian di keenam provinsi tersebut. Dengan demikian program diklat yang direncanakan oleh BPP Jambi merupakan diklat yang dibutuhkan oleh keenam provinsi tersebut. Hal ini berdampak terhadap jenis dan materi diklat yang dilaksanakan oleh BPP Jambi harus dapat menyentuh kebutuhan diklat dari masing-masing provinsi di wilayah pelayanan.

Menyadari pentingnya IKD dalam pelaksanaan diklat, dimana tujuan IKD adalah untuk mengetahui kebutuhan kompetensi yang dibutuhkan oleh calon

\footnotetext{
${ }^{10}$ Sari Rahmawati, op. cit.
} 
peserta diklat, maka penyuluh pertanian yang menjadi peserta diklat di BPP Jambi harus disesuaikan dengan hasil IKD yang sebelumnya telah dilaksanakan. Karena apabila terjadi kesalahan dalam perekrutan calon peserta diklat dalam pelaksanaan diklat, maka materi-materi yang disampaikan selama proses pembelajaran dari awal hingga akhir diklat hanya sekedar memberikan tambahan wawasan yang belum tentu bermanfaat secara nyata bagi peserta diklat maupun instansi/lembaga yang bersangkutan. Hal ini terjadi dikarenakan materi yang diberikan belum tentu dapat diterapkan di wilayah kerjanya untuk mendukung pelaksanaan tugas-tugas pekerjaannya sebagai penyuluh pertanian.

Kita telah melihat bahwa alasan untuk mengembangkan program pelatihan sangat bergantung pada Identifikasi Kebutuhan Diklat, tanpa pemahaman yang jelas tentang kebutuhan diklat, upaya pelatihan yang terbaik sulit dilakukan. Pelatihan hanya akan berhasil jika program yang dikembangkan dan dilaksanakan memenuhi kebutuhan tersebut. Hasil akhirnya adalah gambaran yang lebih tepat tentang kebutuhan pelatihan, yang dapat menyebabkan peningkatan program pelatihan kinerja dan hasil yang lebih baik dari pelatihan.

Hasil Identifikasi Kebutuhan Diklat (IKD) bermanfaat sebagai dasar pengambilan suatu keputusan, disamping memberi solusi/arah, petunjuk tentang apa yang dilaksanakan bagaimana cara melaksanakan dan hasil apa yang diperoleh. Oleh karenanya lembaga pelaksana diklat perlu melaksanakan diklat sesuai dengan hasil IKD. Karena persoalan utama dari suatu diklat bukan tergantung pada sedikit banyaknya diklat yang dilaksanakan tetapi terletak pada kualitas dari diklat itu sendiri.

Balai Pelatihan Pertanian (BPP) Jambi memiliki tugas pokok menyelenggarakan pelatihan di bidang pertanian. Dalam pelaksanaannya BPP Jambi tidak luput dari permasalahan-permasalahan terkait pelaksanaan diklat bagi penyuluh pertanian, salah satunya adalah masih banyak terdapat realisasi peserta yang tidak sesuai dengan hasil pelaksanaan IKD.

Selama tahun 2014, BPP Jambi telah melaksanakan diklat sebanyak 29 (dua puluh sembilan) macam diklat bagi penyuluh pertanian, namun karena terbatasnya anggaran untuk melaksanakan IKD, maka diklat-diklat yang telah dilaksanakan tidak semuanya melalui tahapan IKD yang semestinya dilakukan oleh BPP Jambi. Terhadap diklat-diklat yang tidak dilaksanakan IKD-nya, BPP Jambi melaksanakan kegiatan diklat dengan materi-materi sesuai dengan Standar Kompetensi Kerja Nasional Indonesia (SKKNI) dengan asumsi bahwa peserta diklat membutuhkan seluruh materi yang ada dalam SKKNI untuk menunjang tugas dan pekerjaannya sebagai penyuluh pertanian di lapangan.

Dalam pelaksanaan diklat di tahun 2014, BPP Jambi melaksanakan IKD untuk 11 (sebelas) macam diklat, diklat-diklat yang di IKD-kan adalah: Diklat Teknis Pasca Panen Kedelai Bagi Penyuluh Pertanian, Diklat Teknis Perlindungan Tanaman Hortikultura (komoditas durian) Bagi Penyuluh Pertanian, Diklat Teknis Perlindungan Tanaman Hortikultura (komoditas cabai) Bagi Penyuluh Pertanian, Diklat Teknis Terakreditasi Kelapa Sawit Bagi Penyuluh Pertanian (dua angkatan), Diklat Teknis Kelapa Dalam Bagi Penyuluh Pertanian, Diklat Teknis Pengolahan Hasil Pertanian (komoditas jagung) Bagi Penyuluh Pertanian, Diklat Teknis Pengolahan Hasil Pertanian (komoditas buah naga) Bagi Penyuluh Pertanian, Diklat Teknis Budidaya Jagung Bagi Penyuluh Pertanian, Diklat Teknis Budidaya Padi Bagi Penyuluh Pertanian, Diklat Teknis Terakreditasi 
Budidaya Buah Naga Bagi Penyuluh Pertanian, dan Diklat Teknis Terakreditasi Karet Bagi Penyuluh Pertanian (dua angkatan).

Dalam pelaksanaannya, dari 11 (sebelas) diklat yang telah di IKD-kan hanya terealisasi 7 (tujuh) diklat yang sesuai dengan IKD. Diklat-diklat yang terlaksana tersebut adalah: Diklat Pasca Panen Kedelai Bagi Penyuluh Pertanian, Diklat Teknis Terakreditasi Kelapa Sawit Bagi Penyuluh Pertanian (dua angkatan), Diklat Teknis Pengolahan Hasil Pertanian (komoditas jagung) Bagi Penyuluh Pertanian, Diklat Teknis Pengolahan Hasil Pertanian (komoditas buah naga) Bagi Penyuluh Pertanian, Diklat Teknis Budidaya Jagung Bagi Penyuluh Pertanian, Diklat Teknis Terakreditasi Budidaya Buah Naga Bagi Penyuluh Pertanian, dan Diklat Teknis Terakreditasi Karet Bagi Penyuluh Pertanian.

Terhadap 4 (empat) jenis diklat yang tidak dilaksanakan, hal dikarenakan BPP Jambi menyesuaikan dengan arah kebijakan Kementerian Pertanian, yakni kebijakan Program Upaya Khusus (UPSUS) peningkatan produksi tiga komoditas utama, yakni komoditas padi, jagung, dan kedelai (PAJALE) guna mencapai swasembada pangan yang telah dicanangkan pemerintah. Diklat-diklat tersebut adalah: Diklat Perlindungan Tanaman Hortikultura (komoditas durian) Bagi Penyuluh Pertanian digantikan dengan Diklat Percetakan Sawah Bagi Petugas, Diklat Perlindungan Tanaman Hortikultura (komoditas cabai) Bagi Penyuluh Pertanian digantikan dengan Diklat Teknis Mitigasi dan Perubahan Iklim Bagi Penyuluh Pertanian, Diklat Teknis Kelapa Dalam Bagi Penyuluh Pertanian digantikan dengan Diklat Kepemimpinan Bagi Pengelola Balai Penyuluhan Pertanian, Perikanan, dan Kehutanan (BP3K). Sedangkan untuk Diklat Teknis Budidaya Budidaya Padi tetap dilaksanakan dengan sasaran pesertanya adalah dari unsur TNI, yakni Bintara Pembina Desa (BABINSA). Hal ini dilakukan karena mengingat peran BABINSA dalam pengawalan Program UPSUS PAJALE sangat diperlukan untuk mensukseskan program tersebut.

Sebagai gambaran berikut ini adalah pelaksanaan diklat yang sesuai dengan hasil IKD pada tahun 2014, berdasarkan data penyuluh pertanian yang di IKD dan realisasi peserta dalam pelaksanaan diklatnya.

Tabel 1. Realisasi Peserta Diklat Tahun 2014 Berdasarkan Hasil IKD.

\begin{tabular}{|l|l|l|l|l|}
\hline \multicolumn{2}{|c|}{$\begin{array}{c}\text { DIKLAT TEKNIS TERAKREDIATASI BUAH NAGA } \\
\text { BAGI PENYULUH PERTAIAN }\end{array}$} & \multicolumn{1}{c|}{$\begin{array}{c}\text { DIKLAT TERAKREDITASI KARET BAGI } \\
\text { PENYULUH PERTANIAN ANGKATAN I }\end{array}$} \\
\hline No & \multicolumn{1}{|c|}{ Responden IKD } & \multicolumn{1}{|c|}{ Realisasi Diklat } & \multicolumn{1}{|c|}{ Responden IKD } & \multicolumn{1}{c|}{ Realisasi Diklat } \\
\hline 1 & Syarifuddin & Melati Rosmi, S.P & Victor C Saragih & $\begin{array}{l}\text { Novan Edi Iskandar, } \\
\text { SP }\end{array}$ \\
\hline 2 & Ridwan, S.P & Nazifah, S.P & Lia Susanti & M. Ali, S.ST \\
\hline 3 & Radhiah & Mahdi Rahman & Suer Sepwan Andika & Sudadi, A.Md \\
\hline 4 & Bambang Sutrisno, S.P & $\begin{array}{l}\text { Erpalinda Br. Tarigan, } \\
\text { A.Md }\end{array}$ & Elpin Tamba, A.Md & Elpin Tamba, A.Md \\
\hline 5 & Jainal Sitopu, S.P & Jalaludin, S.P & Jumaidi & Mariyati, SP \\
\hline 6 & $\begin{array}{l}\text { Parlin Jendry } \\
\text { Banjarnahor }\end{array}$ & $\begin{array}{l}\text { Parlin } \\
\text { Banjarnahor }\end{array}$ & Amran, A.Md & Suryati Andriani \\
\hline 7 & Srifatriati & Firdaus, S.Pt & Siti Jaziroh & Maimunah \\
\hline 8 & Evi Susianti, S.ST & Sialani, S.P & Hesti Nugraheni & Berlian Cibro, S.ST \\
\hline 9 & Wirna Lidia & Pebrianto, SP & IT. Rizal, Amd & Darisun \\
\hline 10 & Mardalizen, S.P & Saipul Rizal, SP & Listarianti & Israil \\
\hline 11 & Samsuddin & Suradi, A.Md & Devi Susanti, S.P & $\begin{array}{l}\text { Feri Eko Susanto, } \\
\text { A.Md }\end{array}$ \\
\hline
\end{tabular}




\begin{tabular}{|c|c|c|c|c|}
\hline 12 & Sukardi, S.P & Sutrianti, A.Md & Jalius & Afrianto, S.Pt \\
\hline 13 & Syamrinaldi & Abd. Muin, SP & Zulkifli, S.P & Jalian, SP \\
\hline 14 & Hermaan & Sentosa Ginting & $\begin{array}{l}\text { Lukman Hedriansyah, } \\
\text { S.P }\end{array}$ & Bambang Sudaryanto \\
\hline 15 & Suwarno, S.P & Nurainun & Jamalem Tarigan & Hamidi \\
\hline 16 & Abdul Muas & Herriy, SST & Zainuddin & Rusmaizal R, SP \\
\hline 17 & Lenci Mirza Widia, S.P & Jamaluddin, SP & $\begin{array}{l}\text { Mannus Hutagalung, } \\
\text { S.P }\end{array}$ & Kusnun, S.PKP \\
\hline 18 & Nopriyanti, S.P & Harmaini, SP & Nasbi, S.P & $\begin{array}{l}\text { Rapidin Situmorang, } \\
\text { SP }\end{array}$ \\
\hline 19 & Abdul Kholiq, S.P & M. Sabri, SST & Erman Hajis & Lia Susanti \\
\hline 20 & Syafei & Tenang K, SP & & Sahrial, A.Md \\
\hline 21 & & Haidar, A.Md & & Poltak, A.Md \\
\hline 22 & & Masri Yetti & & Berton Sianturi, SP \\
\hline 23 & & $\begin{array}{l}\text { Haposan Pandiangan, } \\
\text { SP }\end{array}$ & & Tri Lukito, A.Md \\
\hline 24 & & Sri Lestari, S.Pt & & Bajri Yety, S.TP \\
\hline 25 & & Rusmen, A.Md & & $\begin{array}{l}\text { Neli Apriani, SST, } \\
\text { M.Si }\end{array}$ \\
\hline 26 & & Desi Armiaty, SST & & Jamalem Tarigan \\
\hline 27 & & Syafrijal R, A.Md & & Raflis, SP \\
\hline 28 & & Muh. Muhtazar, SP & & Heri Winarto \\
\hline 29 & & $\begin{array}{l}\text { Nelly Apriani, SST, } \\
\text { M.Si }\end{array}$ & & Habonaran Siregar \\
\hline 30 & & $\begin{array}{l}\text { Ir. Zulkfikri Lisonol } \\
\text { Fahmi }\end{array}$ & & Muryanto \\
\hline \multicolumn{3}{|c|}{1 orang sesuai IKD (realisasi sebesar $5 \%$ ) } & \multicolumn{2}{|c|}{1 orang sesuai IKD (realisasi sebesar $5,2 \%$ ) } \\
\hline \multicolumn{3}{|c|}{$\begin{array}{l}\text { DIKLAT TERAKREDITASI KARET BAGI } \\
\text { PENYULUH PERTANIAN ANGKATAN II }\end{array}$} & \multicolumn{2}{|c|}{$\begin{array}{c}\text { DIKLAT TEKNIS TERAKREDITASI KELAPA } \\
\text { SAWIT BAGI PENYULUH PERTANIAN } \\
\text { ANGKATAN I }\end{array}$} \\
\hline No & Responden IKD & Realisasi Diklat & Responden IKD & Realisasi Diklat \\
\hline 1 & Victor C Saragih & $\begin{array}{l}\text { Juni Osmer Saragih, } \\
\text { S.ST }\end{array}$ & Bajikar & Edi Sutrisno, SP \\
\hline 2 & Lia Susanti & A. Hairudin, A.Md & Budi Hantana & Nurliah, SP \\
\hline 3 & Suer Sepwan Andika & $\begin{array}{l}\text { Kapri Tumanggor, } \\
\text { S.ST }\end{array}$ & Martinus, S.P & Syamrizal, A.Md \\
\hline 4 & Jumaidi & A. Fahrurozi & Syamsoel Bahri & Tobrani, S.Pt \\
\hline 5 & Amran, A.Md & Suid Salami & H. Tarmizi G, S.P & Tri Suryani Asih \\
\hline 6 & Siti Jaziroh & Delfin & $\begin{array}{l}\text { Linda Hertati Siburian, } \\
\text { SP }\end{array}$ & $\begin{array}{l}\text { Linda Hertati Siburian, } \\
\text { SP }\end{array}$ \\
\hline 7 & Hesti Nugraheni & Suhendro, S.P & M. Dahlan & Marhadi, S.Pi \\
\hline 8 & IT. Rizal, Amd & Rothmadani, S.P & Fakhruddin S.P & Suid \\
\hline 9 & Listarianti & M. Syahputra Lubis & Kartono Saputro, S.P & $\begin{array}{l}\text { M. Iwan Kurniawan, } \\
\text { SP }\end{array}$ \\
\hline 10 & Devi Susanti, S.P & Hannoveris, S.P & Laila Mutia, S.P & Jamaludin, SP \\
\hline 11 & Jalius & Beni Herianto & Raflis, S.P & Iswandi, SP \\
\hline 12 & Zulkifli, S.P & Musrizal, S.P & Bambang Sudaryanto & Sahrurijal Daulay \\
\hline 13 & $\begin{array}{l}\text { Lukman Hedriansyah, } \\
\text { S.P }\end{array}$ & Wiwi Ratna & Agus Wicaksono, S.P & $\begin{array}{l}\text { Suzan Sri Hastuti, } \\
\text { A.Md }\end{array}$ \\
\hline 14 & Jamalem Tarigan & Darwis S, S.TPi & Didi Carmidi & Warjono, A.Md \\
\hline 15 & Zainuddin & M. Alamin, SP & Hilyanto, S.PKP & Mustafa Kamal, SP \\
\hline 16 & $\begin{array}{l}\text { Mannus Hutagalung, } \\
\text { S.P }\end{array}$ & Abdi Rahmat & Jamal Alnasir & Ucok Harahap, S.PKP \\
\hline 17 & Nasbi, S.P & Darwen & Fajar Siddiq & Pangulu Hutagalung \\
\hline
\end{tabular}

Pelaksanaan Pendidikan dan Pelatihan Bagi Penyuluhan Pertanian oleh Balai Pelatihan Pertanian Jambi Berdasarkan Peraturan Menteri Pertanian 


\begin{tabular}{|c|c|c|c|c|}
\hline 18 & Erman Hajis & $\begin{array}{l}\text { Aswandi Desman, } \\
\text { A.Md }\end{array}$ & Siswadi & Muhammad Ridwan \\
\hline 19 & Fauzan, S.P & Fauzan, S.P & Sutejo, A.Md & Sutejo, A.Md \\
\hline 20 & & Melati Rosmi, S.P & & Erman Hajis \\
\hline 21 & & Suwarno, S.P & & Kapri Tumanggor, SST \\
\hline 22 & & Suarseh, S.P & & Roni Jehan \\
\hline 23 & & Sumarso, S.P & & Rosmawati, SST \\
\hline 24 & & $\begin{array}{l}\text { Panggulung } \\
\text { Hutagalung }\end{array}$ & & Sastera Mulyadi \\
\hline 25 & & Lauser Indrawadi, S.P & & Sadar Bakti Nasution \\
\hline 26 & & Ahmad Junaidi & & Salahuddin, S.PKP \\
\hline 27 & & $\begin{array}{l}\text { Dewantinius F Pandia, } \\
\text { S.P }\end{array}$ & & Hasiah, A.Md \\
\hline 28 & & Dasril. A & & Afrizal \\
\hline 29 & & Suwardi, S.P & & Jamal Alnasir \\
\hline 30 & & Sarko & & Mohammad Isa \\
\hline \multicolumn{3}{|c|}{1 orang sesuai IK (realisasi sebesar 5,2 \%) } & \multicolumn{2}{|c|}{2 orang sesuai IKD (realisasi sebesar $10,5 \%$ ) } \\
\hline \multicolumn{3}{|c|}{$\begin{array}{c}\text { DIKLAT TEKNIS TERAKREDITASI KELAPA } \\
\text { SAWIT BAGI PENYULUH PERTANIAN } \\
\text { ANGKATAN II }\end{array}$} & \multicolumn{2}{|c|}{$\begin{array}{l}\text { DIKLAT TEKNIS BUDIDAYA JAGUNG BAGI } \\
\text { PENYULUH PERTANIAN }\end{array}$} \\
\hline No & Responden IKD & Realisasi Diklat & Responden IKD & Realisasi Diklat \\
\hline 1 & Jamal Alnasir & Ernita Syahril, SP & Asmawit & $\begin{array}{l}\text { Sri Heri Adyono Ty., } \\
\text { SP }\end{array}$ \\
\hline 2 & Hilyanto, S.PKP & Nasbi, SP & Syariyadi, S.PKP & Hasuhutan \\
\hline 3 & Didi Carmidi & Syamsul Rasyid & Dadang Kuswendi & Zulkifli, SP \\
\hline 4 & Agus Wicaksono, S.P & Nofri Harianto, A.Md & Andika Frima Deni & Peramulia, A.Md \\
\hline 5 & Siswadi, SP & Siswadi, SP & Yulizar, S.P & Rita Wati Marbun, SP \\
\hline 6 & Bambang Sudaryanto & $\begin{array}{l}\text { Abdi Cahaya } \\
\text { Buangmanalu, SST }\end{array}$ & Utoyo Raharjo & Beni Herianto \\
\hline 7 & Raflis, S.P & Riko Thomas & Zakwan, S.Pt & Ngadiya, AM,d \\
\hline 8 & Laila Mutia, S.P & Pauwizah, SP & Damsir & Suroto \\
\hline 9 & Kartono Saputro, S.P & Bayu Ilham, S.Pi & Khairuna, S.P & Rahmad Ibrahim \\
\hline 10 & Fakhruddin, S.P & Yayansa, S.ST & Sumarni, S.P & Burhani, AM, d \\
\hline 11 & M. Dahlan & Gusman, SP & Cut Salbiah, S.P., M.P & Joki Sanora \\
\hline 12 & H Tarmizi G, S.P & Hafni, SP & Abu Syari & Juliani MS, SP \\
\hline 13 & Syamsoel Bahri & Mukhlis & Azwar & Hasmarni Z, SP \\
\hline 14 & Martinus, S.P & Urmiati & Junaidi Syafei & $\begin{array}{l}\text { Henny Kusumastuti, } \\
\text { A.Md }\end{array}$ \\
\hline 15 & Fajar Siddiq, A,Md & Fajar Siddiq, A,Md & Fauziah, S.P & Novinsyah Putra \\
\hline 16 & Budi Hantana & Aswadi & Dwi Ari Wibowo & Maryami, SP \\
\hline 17 & Bajikar & Mulyadi & Ega Sugawa, S.P & Ifriati, A.Md \\
\hline 18 & & Paridatul Husni, SP & Mohamad Ali, S.ST & Fevri Roza \\
\hline 19 & & Rasyidin, SP & Rinaldi & Nour Arini, SP \\
\hline 20 & & Winarto, S.TP & Tarwiningsih & Amansyah, SST \\
\hline 21 & & Heiri Yanto, SP & & Saiful Bahri, SST \\
\hline 22 & & Idisda, S.PKP & & Haris, A.Md \\
\hline 23 & & Sardi & & Saridin, SP \\
\hline 24 & & Paryanto, SP & & $\begin{array}{l}\text { Andika Frima Deni, } \\
\text { SST }\end{array}$ \\
\hline 25 & & Syafrijum, SP & & Fakhruddin, SP \\
\hline 26 & & Tarmizi Gt., SP & & Tombang Sirait, A.Md \\
\hline 27 & & Ahmad Saipu & & Eko Sudiharto \\
\hline 28 & & $\begin{array}{l}\text { H. Sepmuda Harahap, } \\
\text { SP }\end{array}$ & & Surya Herlina, SP \\
\hline
\end{tabular}




\begin{tabular}{|c|c|c|c|c|}
\hline 29 & & Jelita Sidebang & & Eriadi Sembiring, SP \\
\hline 30 & & Sri Utami, SP & & Elida Romauli, SP \\
\hline \multicolumn{3}{|c|}{2 orang sesuai IKD (realisasi sebesar $11,7 \%$ ) } & \multicolumn{2}{|l|}{ Realisasi 0\% } \\
\hline \multicolumn{3}{|c|}{$\begin{array}{c}\text { DIKLAT TEKNIS PASCA PANEN KEDELAI BAGI } \\
\text { PENYULUH PERTANIAN }\end{array}$} & \multicolumn{2}{|c|}{$\begin{array}{c}\text { DIKLAT TEKNIS PENGOLAHAN HASIL } \\
\text { PERTANIAN KOMODITAS BUAH NAGA } \\
\text { BAGI PENYULUH PERTANIAN } \\
\end{array}$} \\
\hline No & Responden IKD & Realisasi Diklat & Responden IKD & Realisasi Diklat \\
\hline 1 & Rosniati & Azmiria Fardian & Jaja Kardia, S.PKP & Iskandar \\
\hline 2 & Sri Utami, S.P & $\begin{array}{l}\text { Anik Nur Hidayah, } \\
\text { A.Md }\end{array}$ & Desmaniarti, S.P & Radhiah \\
\hline 3 & Dadi Rosadi & M. Ridwan & Muhammad Nazori & M. Sabri \\
\hline 4 & Arifin Azis, S.P & $\begin{array}{l}\text { Kasnawi Agustina, } \\
\text { SST }\end{array}$ & Sugeng & Erni \\
\hline 5 & Deviant & Sri Wiji, S.PKP & Ucup Supriadi, S.ST & Legiman \\
\hline 6 & Zulfikar, A.Md & Zulfikar, A.Md & Supriadi & Supriadi \\
\hline 7 & Ir. Zainal Abidin, M.P & Sukardi, SP & Asrizal Nusaputra & Sucipto, SPKP \\
\hline 8 & Sugiono & Yasmanidar, SP & Rivaldi & Silvawana, SP \\
\hline 9 & Supardi & Endang Wirdawati, SP & Yendriati & Susriana Fitri, SP \\
\hline 10 & Nurul Safaatiah Sagala & Nurul Safaatiah Sagala & Elka Roza, S.P & Suparman, SP \\
\hline 11 & Syafrinal & $\begin{array}{l}\text { Santa Agnesia } \\
\text { Margaret. P, A.Md }\end{array}$ & Mustakimah & Harmiyati, A.Md \\
\hline 12 & Zakir Nalis & Fransisko & Gindriawan $\mathrm{S}$ & Merry Martin \\
\hline 13 & Suparjono & Antony Athar, SP & Evy Arifin, S.P & Murni, SP \\
\hline 14 & Muhammad, SP & Muhammad, SP & Sukardiono, S.P & $\begin{array}{l}\text { Hadi Sabarudin } \\
\text { Saragih, SP }\end{array}$ \\
\hline 15 & Iskandar, S.Pi & Khairul Saleh, A.Md & Rita Dahlia & Erma HB \\
\hline 16 & Kamismar, A.Md & Elnora Trisna, SP & Nurmiati, S.P & Daita Nofenda \\
\hline 17 & Agus Sunoto & Andri & & Deapra A Siregar, SP \\
\hline 18 & Asri Yanto, S.ST & H. Fakhruddin, SP & & Abdul Kholiq, SP \\
\hline 19 & Hamidi & Julian, S.PKP & & Zahara Pikadar \\
\hline 20 & Arliza, S.P & Ihwayan Siregar & & Ratnawati, S.PKP \\
\hline 21 & & Yul Bakri & Hasan Basri, S.P & Hasan Basri, SP \\
\hline 22 & & Mulyanto, S.PKP & & $\begin{array}{l}\text { Eva Harpalaini BR. } \\
\text { Ginting, S.TP }\end{array}$ \\
\hline 23 & & Sumardi & Zuhra, A.Md & Zuhra, A.Md \\
\hline 24 & & $\begin{array}{l}\text { Putri Indah Hayati, } \\
\text { S.TP }\end{array}$ & & Goklas MH Silalahi \\
\hline 25 & & Kasmir & Lastiar M. Purba, SP & Lastiar M. Purba, SP \\
\hline 26 & & Syafrijal & Siti Maisaroh, S.PKP & Siti Maisaroh, S.PKP \\
\hline 27 & & Mardiana, S.TP & & Zulfajri Umran \\
\hline 28 & & Satria Irawan, A.Md & & Siti Jaziroh, SP \\
\hline 29 & & $\begin{array}{l}\text { Halasson H Nadapdap, } \\
\text { S.Pt }\end{array}$ & & Yuliyar Syafar \\
\hline 30 & & Marsono, SST & & Rahmad Syah, SP \\
\hline \multicolumn{3}{|c|}{2 orang sesuai IKD (realisasi sebesar $10 \%$ ) } & \multicolumn{2}{|c|}{5 Orang sesuai IKD (realisasi sebesar $25 \%$ ) } \\
\hline \multicolumn{3}{|c|}{$\begin{array}{l}\text { DIKLAT TEKNIS PENGOLAHAN HASIL } \\
\text { PERTANIAN KOMODITAS JAGUNG BAGI } \\
\text { PENYULUH PERTANIAN }\end{array}$} & & \\
\hline No & Responden IKD & Realisasi Diklat & & \\
\hline 1 & N Chairuddin, S.P & $\begin{array}{l}\text { Masderiana Harahap, } \\
\text { SP }\end{array}$ & & \\
\hline 2 & Rohaman & Erni & & \\
\hline
\end{tabular}

Pelaksanaan Pendidikan dan Pelatihan Bagi Penyuluhan Pertanian oleh Balai Pelatihan Pertanian Jambi Berdasarkan Peraturan Menteri Pertanian 


\begin{tabular}{|c|c|c|}
\hline 3 & Ali Surdi & $\begin{array}{l}\text { Dedek Kurniawan, } \\
\text { A.Md }\end{array}$ \\
\hline 4 & Jusnimar & Fara Shaliza, SP, M.Si \\
\hline 5 & Irwan Jonis, A.Md & Ir. Ramli \\
\hline 6 & Epi Sukaini & Yayansa, SST \\
\hline 7 & $\begin{array}{l}\text { Rodiah Syukriyanti, } \\
\text { S.P }\end{array}$ & Tukiyo \\
\hline 8 & Hj. Gustina, S.P & Herry Pramona, S.Pt \\
\hline 9 & Darmawai & Ali Surdi \\
\hline 10 & Jhon Notris, S.P & Darnis, SP \\
\hline 11 & Ir. Yenni Aswati & $\begin{array}{l}\text { Paber Hasudungan, } \\
\text { A.Md }\end{array}$ \\
\hline 12 & Erna Mariance Sitinjak & Erna Mariance Sitinjak \\
\hline 13 & Nasir Rosidi, A.Md & $\begin{array}{l}\text { Sukardi Brata, S.Pd, } \\
\text { SST }\end{array}$ \\
\hline 14 & Paima, A.Md & Juweni \\
\hline 15 & Sri Asih & Helmi Hayati \\
\hline 16 & Muhammad Yunus & Hermadi \\
\hline 17 & Yasmanidar, S.P & Zulniarti, SST \\
\hline 18 & Nuraini, MS & $\begin{array}{l}\text { Edy Jonter H. } \\
\text { Pandiangan, SP }\end{array}$ \\
\hline 19 & Cut Chairiah, S.ST & Zulfikar \\
\hline 20 & Yusri, S.P & $\begin{array}{l}\text { Dede Sahputra } \\
\text { Harahap, A.Md }\end{array}$ \\
\hline 21 & & Ade Suhendar, SP \\
\hline 22 & & Siti Mainar, SP \\
\hline 23 & & Siti Jaziroh, A.Md \\
\hline 24 & & Vera Nope Lina, SP \\
\hline 25 & & Rusli \\
\hline 26 & & $\begin{array}{l}\text { Mira Ayudya Modesa, } \\
\text { SP }\end{array}$ \\
\hline 27 & & Ulia Rahmadhani, SP \\
\hline 28 & & Dina Maya S, SP \\
\hline 29 & & $\begin{array}{l}\text { Soerantri Poedji } \\
\text { Hastoeti }\end{array}$ \\
\hline 30 & & \\
\hline
\end{tabular}

Sumber kuisioner pelaksanaan IKD tahun 2014 dan laporan pelaksanaan diklat 2014 BPP Jambi.

Sedangkan pada tahun 2015, BPP Jambi telah melaksanakan diklat sebanyak 8 (delapan) macam diklat bagi penyuluh pertanian yang terlaksana sebanyak 25 (dua puluh lima) angkatan, tetapi tahapan IKD sebelum pelaksanaan diklat hanya dilakukan untuk 2 (dua) macam diklat, diklat tersebut adalah: Diklat Budidaya Jamur Tiram Bagi Penyuluh Pertanian, dan Diklat Teknis Kelapa Sawit Bagi Penyuluh Pertanian. Sebagai gambaran realisasi peserta diklat terhadap hasil IKD tertera dalam tabel di bawah.

Tabel 2. Realisasi Peserta Diklat Tahun 2015 Berdasarkan Hasil IKD. DIKLAT BUDIDYA JAMUR TIRAM BAGI PENYULUH PERTANIAN DIKLAT TEKNIS KELAPA SAWIT BAGI PENYULUH PERTANIAN

\begin{tabular}{|l|l|l|l|l|}
\hline No & \multicolumn{1}{|c|}{ Responden IKD } & \multicolumn{1}{|c|}{ Realisasi Diklat } & \multicolumn{1}{c|}{ Responden IKD } & \multicolumn{1}{c|}{ Realisasi Diklat } \\
\hline 1 & Erita Efenti & Sapriani Dewi, SP & Sahril & M. Nasir, S.PKP \\
\hline 2 & Franki S.P & Islara Sri Maya, S.Pt & Quirino Leontif & Joko Purwadi, A.Md \\
\hline
\end{tabular}




\begin{tabular}{|c|c|c|c|c|}
\hline 3 & Ir. Yenni Aswat & Ir. Yenni Aswat & Zicco Esa Putera & Zuhdi Iskandar \\
\hline 4 & Naswer, A.Md & Naswer, A.Md & Hayan & Dudi Herdawan, SP \\
\hline 5 & Sri Lestari, S.Pt & Sri Lestari, S.Pt & Jhon Hendra & Hasril, S.Pt \\
\hline 6 & Risayezi, S.P & Suryati & Elka Roza, S.P & Dadi Rosadi \\
\hline 7 & Yuliati Kurnia Sari, SP & Yuliati Kurnia Sari, SP & Muhammad, SP & Muhammad, SP \\
\hline 8 & Khumaidi & Hamidi & M. Najid, A.Md & Lenci Mirza Widia, SP \\
\hline 9 & Martalena & H. Ahmad Sofyan, SP & Pairul, S.PKP & Fitria, S.Pt \\
\hline 10 & Harius Totel & Afdiron Novindra & Darsis, S.PKP & Darsis, S.PKP \\
\hline 11 & Rully Ekayanti A, S.P & Apriyanti, SP & Rita Wati Marbun, SP & Rita Wati Marbun, SP \\
\hline 12 & T. Hardiani, S.P & Dasmawati, SP & Sialani, S.P & Priyudi. R.A. Damanik \\
\hline 13 & Zuhrul Aeni & Hotobri & Syafrinal & Syafrinal \\
\hline 14 & Reno & Dudung Hidayat & Trisatnowo & Agung Prasetyawan, SP \\
\hline 15 & Armentri & Armentri & Syahril & Hasanuddin Nasution \\
\hline 16 & Rosnawati, SP & Rosnawati, SP & $\begin{array}{l}\text { Anik Nur Hidayah, } \\
\text { A.Md }\end{array}$ & Margina, SST \\
\hline 17 & Mutia Laila, S.PKP & Suratno & Rosdi Arifin, S.Pt & Jamaluddin, SP \\
\hline 18 & Asyari, A.Md & Deti Tesmita & Aprijal, S.PKP & Supomo \\
\hline 19 & Hesti Nugraheni, B.Sc & Paryanto, SP & Yulizar, SP & Yulizar, SP \\
\hline 20 & Denok & Melda, SP & Effendi Sianipar, S.P & Indrayadi, SP \\
\hline 21 & Suparmi & Ir. Ramli & Afrizal, A.Md & Afrizal, A.Md \\
\hline 22 & Kasirun, STP & Kasirun, STP & Tri Lukito, A.d & Zikri \\
\hline 23 & Eka Lukiana, S.P & Armanto, SP & Supandi, S.ST & Widodo \\
\hline 24 & Fakhrurozi, S.P & Tri Lukito, A.Md & Sarpo, S.P & Sialani, SP \\
\hline 25 & Alfan, S.P & Julian Syahputra & Kaya Amin H, S.P & Teuku Mursalahuddin \\
\hline 26 & Ir. Ardanus, M.Si & Ir. Ardanus, M.Si & Ujang. DH & Ujang. DH \\
\hline 27 & Lita Susyanti & Nur Ainun & Sudarsih, S.Pt & Sudarsih, S.Pt \\
\hline 28 & Iskandar & Gusniar Chan, SP & Muzaijin & Jalius, SP \\
\hline 29 & Joki Sanora & Sugianto & Yulian RS, S.P & Izuddin, SP \\
\hline 30 & & B. Ero, SST & & Yayansa, SST \\
\hline \multicolumn{3}{|c|}{8 orang sesuai IKD (realisasi sebesar $27,5 \%$ ) } & \multicolumn{2}{|c|}{8 orang sesuai IKD (realisasi sebesar $27,5 \%$ ) } \\
\hline
\end{tabular}

Sumber laporan pelaksanaan IKD tahun 2015 dan laporan pelaksanaan diklat 2015 BPP Jambi.

Berdasarkan tabel 5 dan tabel 6 di atas, kita ketahui bahwa tidak ada satu diklat pun yang menunjukkan bahwa rekrutmen terhadap peserta diklat yang mencapai $100 \%$ dari responden IKD yang telah dilakukan identifikasi kebutuhannya dalam diklat, bahkan pada tahun 2014 realisasi peserta diklat yang sesuai dengan IKD yang tertinggi adalah 25\%, dan pada tahun 2015 hanya sebesar $27,5 \%$, penghitungan persentase realisasi alokasi peserta diklat yang peneliti ambil adalah jumlah perbandingan responden IKD secara keseluruhan dengan realisasi peserta diklat, terlepas dari jumlah peserta diklat yang dilaksanakan sebanyak 29-30 orang setiap angkatan.

Dengan rekrutmen peserta diklat yang sesuai dengan hasil IKD tidak mencapai $30 \%$, jelas terjadi selama pelaksanaan diklat pada saat proses berlatih dan melatih berlangsung telah terjadi ketidaksesuaian kebutuhan sebagian besar peserta diklat akan materi-materi yang disampaikan selama mengikuti diklat. Hal ini tentunya tidak sesuai dengan amanah peraturan perundangan yang berlaku, karena menurut Peraturan Menteri Pertanian Nomor 49 tahun 2011, disebutkan bahwa "IKD adalah suatu proses analisis membandingkan antara SKK dengan KKN untuk mendapatkan kekurangan kompetensi kerja". Bahkan dipertegas lagi oleh Lembaga Administrasi Negara (LAN) bahwa "kebutuhan diklat adalah kekurangan pengetahuan, ketrampilan dan sikap seorang pegawai sehingga 
kurang mampu melaksanakan tugas, tanggung jawab, wewenang dan haknya dalam suatu satuan organisasi". ${ }^{11}$

Secara umum pendidikan dan pelatihan pertanian bertujuan untuk memberikan kesempatan kepada penyuluh pertanian dalam meningkatkan pengetahuan, sikap, dan keterampilan mereka, terutama dalam bidang-bidang yang berhubungan dengan tugas-tugas dari pekerjaan penyuluh pertanian di lapangan. Jika tujuan IKD adalah untuk mengetahui kompetensi apa saja yang harus diisi melalui pelaksanaan diklat, maka idealnya adalah seluruh peserta dalam diklat harus sesuai dengan responden IKD. Hal ini dimaksudkan agar kurikulum diklat yang dihasilkan dari pelaksanaan IKD benar-benar memberikan manfaat yang nyata bagi penyuluh pertanian dan dapat diterapkan di wilayah kerjanya. Dengan demikian, diharapakan tujuan dari penyuluhan itu sendiri dapat dilakukan secara maksimal oleh penyuluh pertanian di lapangan, yang mana tujuan penyuluhan adalah untuk menumbuhkan perubahan-perubahan dalam diri petani yang mencakup tingkat pengetahuan, sikap, keterampilan, dan motivasi petani terhadap kegiatan usaha tani yang dilakukan untuk meningkatkan kesejahteraan petani.

Dari uraian di atas, dapat dilihat bahwa Balai Pelatihan Pertanian (BPP) Jambi dalam merekrut peserta diklat hanya sebagian kecil yang sesuai dengan hasil IKD. Hal ini mengakibatkan kekurangan kompetensi dari peserta diklat yang akan diisi atau dihilangkan melalui program diklat hanya sebagian kecil yang tepat sasaran, hal disebabkan karena sebagian besar rekrutmen peserta diklat yang tidak berbanding lurus dengan responden IKD.

Dalam wawancara yang peneliti lakukan dengan Kepala Balai Pelatihan Pertanian Jambi, yakni Bapak Dr. Ir. Teddy Rachmat Muliady, M.M, beliau mengatakan:

"Inilah dilema penyelenggaraan diklat, jadi kadang-kadang calon atau sasaran IKD ini yang ditunjuk oleh pihak daerah (kabupaten) bukan yang nantinya akan menjadi peserta pelatihannya. Ini sangat mengganggu sebetulnya. Mengganggunya dimana? Karena kebutuhan pelatihan bagi para penyuluh setiap orang ini tentunya berbeda. Baik kapasitasnya saat itu. Jadi intinya kurikulum yang lahir dari IKD belum tentu cocok pada saat perserta latih itu sudah ada di balai ini". ${ }^{2}$

Hal senada pun dinyatakan oleh Kepala Seksi Penyelenggaraan Pelatihan BPP Jambi, Bapak Purnadi, S.P., M.P, ketika peneliti menanyakan dan menyatakan bahwa peserta diklat haruslah sesuai dengan hasil IKD, beliau menjawab:

"Kalau saya sependapat itu, karena ketika kita meng-IKD seseorang bahwa yang kita ukur itu adalah kemampuan mereka, dan tidak menutup kemungkinan bahwa itu sebagai sampel bagi wilayah itu sendiri secara keseluruhan, secara umum bahwa kemampuan petugas yang di sana dapat

\footnotetext{
${ }^{11}$ Huma Silva, "Identifikasi Kebutuhan Diklat". Diakses dari

http://humasilva.blogspot.co.id/2009/02/identifikasi-kebutuhan-diklat.html pada tanggal 19 maret 2016, pukul 20.00.

12 wawancara dengan Kepala BPP Jambi, Teddy Rachmat Muliaddy, tanggal 7 Maret 2016, di komplek Balai Pelatihan Pertanian Jambi.
}

Pelaksanaan Pendidikan dan Pelatihan Bagi Penyuluhan Pertanian oleh Balai Pelatihan Pertanian Jambi Berdasarkan Peraturan Menteri Pertanian 
kita ukur dengan IKD. Sehingga memang kalau bisa siapa yang kita IKD itulah orang yang kita panggil untuk mengikuti diklat."13

Dalam pelaksanaan diklat, sejatinya respnden pada pelaksanaan IKD adalah sebagai peserta dalam diklat, namun kenyataannya yang terjadi adalah realisasi peserta diklat hanya sebagian kecil yang sejalan dengan penetapan responden Identifikasi Kebutuhan Diklat (IKD). Bagi peserta diklat yang tidak sesuai dengan hasil IKD, maka dalam proses pembelajaran setiap materi yang disampaikan oleh pelatih belum tentu menjadi kebutuhan dari peserta yang bersangkutan.

Jika hal tersebut di atas terjadi, maka peserta diklat yang bersangkutan akan merasa jenuh dan kurang serius dalam mengikuti proses pembelajaran. Dalam pelaksanaan diklat, sesuai dengan Peraturan Menteri Pertanian Nomor 49 Tahun 2011 BAB III Penyelenggaraan Pendidikan dan Pelatihan Pertanian, Huruf C Tahapan Penyelenggaraan Diklat Pertanian menyebutkan bahwa:

"Identifikasi Kebutuhan Diklat (IKD) dilakukan untuk memperoleh Kekurangan Kompetensi Kerja (KKK). Selisih antara SKK dengan Kompetensi Kerja Nyata (KKN) adalah KKK. IKD diperoleh dengan cara merumuskan dan menyusun SKK/SKKNI serta melaksanakan identifikasi kekurangan kompetensi kerja untuk kebutuhan diklat yang diperoleh dari calon peserta".

IKD tersebut di atas, dilaksanakan sebelum pelaksanaan diklat dan yang menjadi responden adalah calon peserta diklat yang di IKD-kan, hal ini dimaksudkan agar materi pembelajaran selama diklat berlangsung sesuai dengan kebutuhan dari peserta diklat dan tentunya dapat diaplikasikan di Wilayah Kerja Penyuluh Pertanian (WKPP). Lebih jauh lagi diklat yang diikuti oleh penyuluh pertanian dapat membawa manfaat nyata bagi penyuluh itu sendiri dan petanipetani binaannya dalam rangka alih teknologi yang lebih baik.

\section{KESIMPULAN}

Berdasarkan uraian yang penulis kemukakan pada bab-bab sebelumnya, maka penulis dapat mengemukakan sebagai kesimpulan sebagai berikut:

Tidak semua diklat yang dilaksanakan oleh BPP Jambi melalui tahapan IKD. Realisasi peserta diklat yang dilaksanakan selama tahun 2014 hingga 2015 sebagian besar tidak sesuai dengan hasil dari IKD. Realisasi tertinggi dari peserta diklat yang sesuai dengan IKD pada tahun 2014 adalah 25\% dan terendah terendah adalah $0 \%$, sedangkan realisasi peserta yang sesuai dengan hasil IKD pada tahun 2015 adalah sebesar 27,5\%.

\section{DAFTAR PUSTAKA}

Departemen Pertanian, Manajemen dan Perencanaan Pelatihan, Badan Pengembangan Sumberdaya Manusia Pertanian, Jakarta, 2004.

Departemen Pertanian, Pedoman Penyelenggaraan Diklat Pertanian Buku 2 Perencanaan Diklat, Badan Pengembangan Sumberdaya Manusia Pertanian, Jakarta, 2003.

H.M. Hadin Muhjad dan Nunuk Nuswardani, Penelitian Hukum Indonesia Kontemporer, Genta Publishing, Yogyakarta, 2012.

${ }^{13}$ Wawancara dengan Kepala Seksi Penyelenggaraan Pelatihan BPP Jambi, Purnadi, tanggal 20 Maret 2016, di Desa Pondok Meja.

Pelaksanaan Pendidikan dan Pelatihan Bagi Penyuluhan Pertanian oleh Balai Pelatihan Pertanian Jambi Berdasarkan Peraturan Menteri Pertanian 
Rochaeni Siti, 2014, Pembangunan Pertanian Indonesia, Graha Ilmu, Jakarta, 2014.

Suratman dan Dillah Philips, 2012, Metode Penelitian Hukum, Alfabeta Bandung, Malang, 2012.

Sugiono, 2003, Metode Penelitian Administrasi, Alfabeta Bandung, Malang, 2013.

Sumber Lain:

BPPSDMP, Rencana Strategis 2015-2020 Pusat Pelatihan Pertanian, Badan Penyuluhan dan Pengembangan SDM Pertanian, Jakarta, 2015.

BPP Jambi, Road Map Balai Pelatihan Pertanian Jambi, Balai Pelatihan Pertanian Jambi, Jambi, 2015.

Laporan Pelaksanaan Identifikasi Kebutuhan Diklat Balai Pelatihan Pertanian Jambi Tahun 2014.

Laporan Pelaksanaan Identifikasi Kebutuhan Diklat Balai Pelatihan Pertanian Jambi Tahun 2014.

Internet:

http://adman.staf.upi.edu/files/2009/08/KONSEP-PELATIHAN.doc

http://docplayer.info/351397-Laporan-kajian-pedoman-penyusunan-analisis-

kebutuhan-diklat-akd-dan-identifikasi-kebutuhan-diklat-ikd-kerjasama-pt-

idi-kajang-consultans-dengan.html diakses pada tanggal 1 maret, pukul 10.00 WIB.

http://female.store.co.id/images/media/administrasi-negara-full.pdf diakses pada tanggal 17 oktober 2015, pukul 20.07 WIB.

http://humasilva.blogspot.co.id/2009/02/identifikasi-kebutuhan-diklat.html diakses pada tanggal 19 maret 2016, pukul 20.00 WIB.

http://masimamgun.blogspot.co.id/2010/04/pendidikan-dan-pelatihan-sumberdaya.html diakses pada tanggal 12 November 2015, pukul 20.23 WIB. http://www.bppjambi.info/?v=pr\&id=123.

Perundangan:

Peraturan Menteri Pertanian Nomor 49/Permentan/OT.140/9/2011 Tentang Pedoman Pendidikan dan Pelatihan Pertanian Aparatur dan Non Aparatur.

Peraturan Menteri Pertanian Nomor 88/Permentan/OT.140/6/2014 Tentang Rincian Tugas Pekerjaan Unit Kerja Eselon IV Balai Pelatihan Pertanian Jambi

Pelaksanaan Pendidikan dan Pelatihan Bagi Penyuluhan Pertanian oleh Balai Pelatihan Pertanian Jambi Berdasarkan Peraturan Menteri Pertanian 